\title{
THE STATE OF NURSING REGULATION
}

Professor Sinegugu Duma: University of Cape Town)

\section{Abstract}

The regulation of the nursing profession and the protection of the public in general health service and nursing practice matters has been the main responsibility of the South African Nursing Council in South Africa since its inception in 1944. This is done through the four main functions that have remained unchanged throughout the decades. These include the regulation of the education and training of nurses and midwives through provision of relevant regulations; licencing of nurses and midwives to practise the profession of nursing and midwifery; ensuring quality nursing practice and advising the Minister and influencing health-related policies.

This chapter describes the state of the nursing regulation since the inception of the South African Nursing Council as an autonomous statutory body for the nursing profession and its objectives and the mandatory functions. It further highlights the historical devel opments and changes that have occurred in the nursing profession as a self-regulating profession that is dynamic and responsive to the national regulations and developments affecting the practice and education of nurses and midwives, including the health needs of the country.

The achievements, the challenges and opportunities for the South African Nursing Council highlight the current state of the nursing regulation in South Africa.

Keywords: Regulation; SANC; State of Nursing.

\section{Introduction}

The nursing and midwifery professions in South Africa are regulated mainly by the South African Nursing Council (SANC) which is a professional body, entrusted to set and maintain standards of nursing education and practice. SANC is an autonomous statutory body, established by the Nursing Act, No. 45 of 1944, amended by the Nursing Act, No. 50 of 1978 and the current Nursing Act 33 of 2005. It is financed through the licensing, registration and accreditation fees paid by nurses and nursing education institutions and is therefore independent.

The South African Nursing Council regulates the nursing professions through the following functions:

- Development, maintenance, promotion and control of standards in nursing education and training;

- Registration of different categories of nurses and midwives in the country and

- Monitoring the ethical and professional conduct of nurses and midwives.

The new democratic South African government of 1994 established the unified regulation of nursing in the Republic through the enactment of the Nursing Amendment Act of 1995 (Act 547 of 1995). Among other things, this Act provided for the establishment of the South African Interim Nursing Council and the abolition of the various nursing councils of the self-governing homelands which were established under section 26 of the Self-Governing Territories Constitution Act, 1971 (ACT No. 21 of 1971) by the apartheid government. The abolished councils included the Bophuthatswana Nursing Council which was 
established by section 53 of the Health and Related Act of 1985 (Bophuthatswana); the Ciskeian Nursing Council which was established by section 2 of the Nursing Act (Act 13 of 1984) of Ciskei and the Transkei Nursing Act which was established by section 2 of the Nursing Act of 1978 (Act No. 6 of 1978) of Transkei (Nursing Amendment Act, 1995).

As it is seen in its predecessors, the Nursing Amendment Act of 1995 was designed to support the universal norms and values of the nursing profession, placing emphasis on professional practice, democracy, transparency, equity, accessibility and community involvement in line with the legislative goals of the newly established democraticorder. However, the Act did not eliminate the provisions of the Nursing Act of 1978 (Act No. 50 of 1978) which still gives the nursing profession its self-regulating powers.

The Nursing Amendment Act of 1995 was amended by the Nursing Amendment Act of 1997 (Act 19 of 1997) which provided for the abolition of the South African Interim Nursing Council in readiness for the Nursing Act of 2005 (Act No. 33 of 2005).

\section{Changes in the Nursing Act}

The most important function that has remained unchanged in the Nursing Act since its inception in 1944, is its mandate in the regulation of the nursing profession through the South African Nursing Council as a juristic entity and its objects. These include the protection of the publicin matters involving health services in general and the nursing practice in particular. The following functions of the South African Nursing Council have also remained unchanged throughout the decadesi.e. the regulation of the education and training of nurses and midwives through provision of relevant regulations; licensure of nurses and midwives to practice the profession of nursing and midwifery; ensuring quality nursing practice and advising the Minister and influencing health-related policies (Nursing Act, 2005).

The changes that occurred in the general legislation of the country as it evolved from an apartheid system to a fully fledged democracy had some influence on the regulation of the nursing profession. This is evidenced by a number of amendments to the Nursing Acts leading to the new Nursing Act 33 of 2005. The number of Amendment Acts since 1944 indicate that the nursing profession as a self-regulating profession is dynamic and responsive to the national regulations and developments affecting the practice and education of nurses and midwives, including the health needs of the country. The incorporation of all the "homeland" nursing councils into the main South African Nursing Council is a good example of the nursing regulatory body's response to the national changes. This was as a result of the Constitution Act 108 of 1996, which aimed to redress all the past unfair discriminatory laws and practices such as the segregation of the nursing profession into different nursing councils based on racial discrimination.

\section{Changes in response to the Higher Education Act 101 of 1997}

The amended Higher Education Act 101 of 1997 plays a significant role in the current changes within nursing regulation, specifically with regard to the regulation of education and training of professional nurses (Marock, 2000). For instance, the Council of Higher Education (CHE), which has a statutory responsibility for assuring higher education through the Higher Education Act 101 of 1997, influenced the regulation of the nursing education programmes offered by universities in the country. 
The Higher Education Act 101 of 1997 is mandated, among other things, to regulate higher education; provide for the establishment, composition and functions of a Council on Higher Education; facilitate the registration of private higher education institutions and to enable quality assurance and quality promotion in higher education through the Council for Higher Education (Badat, 2003).

The main functions of the Council for Higher Education, through the Higher Education Quality Committee (HEQC), are:

- To promote quality assurance in higher education;

- To audit the quality assurance mechanisms of higher education institutions;

- To accredit providers of higher education institutions offering programmes leading to particular National Qualification Framework (NQF) registered qualifications.

The above functions have always been embedded within the central mandate of the So uth African Nursing Council, whose tasks included:

- Prescription of the minimum standards for education and training of nurses and midwives;

- Approval of all nursing schools and nursing education institutions (including nursing departments at universities);

- Approval of all nursing education programmes;

- Registration and enrolment of nurses (Marock, 2000).

By virtue of the Higher Education Act 101 of 1997, the HEQC could take over the first three tasks from the South African Nursing Council. The SANC would retain the task of registration or enrol ment of nurses and midwives. However, as qualifications specifically target preparation for a specific profession or occupation, input from the profession might be needed. This debate has not received much formal attention in the nursing arena, although the complexity of the quality assurance process for nursing has been causing much frustration in the profession.

Although, in principle, the separation of roles between the HEQC and professional regulatory bodies such as the SANC seems simple on paper, in practical terms it has remained difficult, as professional regulatory bodies have always been the main quality assurers. They were responsible for setting professional and educational standards and for evaluating the quality of their implementation as they saw fit. A practical solution to the problem came through the recognition of the professional regulatory bodies as Education and Training Quality Assurance (ETQA) bodies in terms of the South African Quality Authority Act of 1995 (Act No. 58 of 1995).

\section{The South African Nursing Council as an Education and Training Quality Assurance Authority}

AAssurance body in November 2001 in terms of section 5(1) (a) (ii) of the South African Qualification Authority Act No. 58 of 1995. This was regarded as an achievement and a complement to the SANC's original statutory functions of protecting the public through ensuring quality nursing education (Subedar, 2001). It was an achievement because it meant that the SANC met all the requirements for accreditation of professional bodies as ETQAs. In addition to the SANC's original functions as an ETQA, the SANC was now accredited to:

- Facilitate moderation among constituent providers; 
- Registerassessors;

- Co-operate with relevant moderating bodies;

- Recommend new standards or qualifications to National Standard Bodies or modify existing standards and qualifications;

- Submit reports toSAQA.

The South African Nursing Council later recognized all qualified and registered nurse educators (tutors) as assessors and moderators. Professional nurses who do not have a nursing education qualification, but are involved in the assessment of learners and want to be accredited as assessors and moderators, still need to undergo assessor or moderator training in order to be registered as assessors by the SANC and thus assist the SANC to retain its obligations as an ETQA.

In 2008, in recognition of its new status as an ETQA, a new committee, namely the accreditation committee, was added to the standing committees of the SANC. The main responsibility of this Accreditation Committee is to ensure that institutions intending to conduct nursing education and training programmes prepare nurses to meet the prescribed standards and conditions for education and training (Nursing Act, 2005). Among other things, the committee, in collaboration with the Education Committee and the Laws, Practice and Standards Committee, developed the rules and regulations for accreditation of nursing education institutions.

In order to fulfill the role of quality assurance and accreditation of nursing education institutions and nursing education programmes, the SANC has proposed that levy fees for these activities be paid by the nursing education institutions through a new regulation. The regulation was submitted for public comment considering that nursing education entities had not paid for accreditation, re -accreditation and programme approval in the past. Some nursing professional organisations are of the view that the proposed regulation for fees associated with accre ditation should first have been debated by the nursing profession. At least the SANC can specify the specific services that it will be rendering, how much these cost and how they will benefit the nursing education institutions in terms of increased efficiency. Furthermore, nursing organisations need to be informed that the levies paid to professional councils for accreditation of education programmes do not pertain to nursing education alone, but to all other professional councils which have an ETQA responsibility. Having access to such knowledge is important for nursing organisations and the public.

\section{The licensure of nurses}

The licensure of nurses has remained an unchanged instrument of the SANC in protecting the public through the Nursing Act, by ensuring that no persons may practise nursing or midwifery in the country unless they are registered to practise in the following categories: professional nurse, midwife, staff nurse, auxiliary nurse or auxiliary midwife (Nursing Act, 2005).

Over the years this was done through registration or enrolment on proof of a qualification by an applicant. A NEI and specific programmes in nursing were approved by the SANC. When a student completed such a programme, they were, on application, automatically registered by the SANC. To be aligned with international standards, the SANC is currently exploring the possibility of licensure of nurses and midwives through national examinations. It is argued that this will ensure that all nurses and midwives entering the nursing profession meet the same national nursing standards. This is also one of 
the core functions of the SANC as stated in the Nursing Act 33 of 2005 Section 4(c) i.e. to conduct examinations and grant certificates in respect of such examinations. However, there are problems related to such a centralized system. One issue is the high cost in creating an efficient, reliable, valid and equitable system. In addition, there is the problem of the SANC setting standards and also being the ETQA, which is not usual in the ETQA system in the country. The latter demonstrates the complexity and conflict of roles for the SANC as an ETQA and a standard-setting body. The current absence of the nursing standards further complicates this matter and highlights the urgency for the SANC to develop the nursing standards in consultation with the nursing professional organisations.

\section{Changes in response to the Further Education and Training Act No 98 of 1998}

The Further Education and Training Act No. 98 of 1998 is mandated to regulate further education and training, to provide for quality assurance and quality promotion in further education and training, and to ensure the registration of private further education and training institutions. According to the Further Education and Training Act, further education and training encompasses "all learning and training leading to a qualification from NQF level 2 to 4 ".

A large proportion of the other categories of nurses are currently trained at both public and private nursing colleges and nursing schools under the Further Education and Training Act. Although this is clear from the Act, the positions of the nursing colleges which conduct nursing education and training at a 4year diploma level and post basic nursing programmes which are above NQF level 4 have not been properly determined. Most of the private nursing schools and colleges have since registered under the Further Education and Training Act No. 98 of 1998. Currently, public nursing colleges remain affiliated to universities which are registered under the Higher Education Act. The position of the public nursing schools (those attached to hospitals) remains unclear with regard to registration under the Further Education and Training Act No 98 of 1998, although these colleges are approved to offer nursing education programmes.

The SANC, in consultation with relevant offices, including CHE and the National Department of Health (which is the custodian of all public nursing colleges and hospitals), is currently investiga ting ways of ensuring that the public nursing colleges and nursing schools meet the national education legislation requirements.

\section{The regulation of nurses with impairments}

One of the achievements of the South African Nursing Council is the recognition of the need to regulate the management of those nurses and midwives who are precluded from practising due to mental or physical impairments. In the past the disciplinary process of the Council focused on ensuring the safety of patients (by preventing the nurse or midwife from practising so that patients were safeguarded) without addressing the problems of the nurse or midwife by means of rehabilitation.

Since 2008, an additional standing Impairement Committee was established for the purpose of moving towards a more supportive approach. The focus of the Impairment Committee is the rehabilitation of the incapacitated practitioner, aimed at assisting him or her to address the problem before returning to practise so as to ensure the safety of the public. To do this, the committee appoints professionals with relevant expertise and experience as assessors to advise the Council on whether it would be detrimental 
to the public interest to allow an incapacitated practitioner to continue practising as a nurse or midwife or to put measures in place so as to ensure that the practitioner is eventually enabled to return to work.

Over the past two years, nurses who would previously have been removed from the profession due to mental or physical impairment have been supported by the Impairment Committee processes. The progress of those who have returned to practising is currently being monitored and the outcomes seem favourable.

The challenge of the SANC is to inform health service managers and nurse practitioners about the committee and its aims in order to establish who requires its services. The success of the committee depends upon the dissemination and utilisation of such knowledge.

\section{Criticism of the SANC}

The South African Nursing Council has recently received criticism over a number of issues. These were raised at different nursing and community forums. Some of the criticisms include the inability to keep abreast with changes in the health and education system, failure or delays in meeting all its functions and the lack of recognising midwifery as a profession in its own right.

\section{The new qualifications and the scope of practice}

In 2010, a new framework for nursing qualifications was accepted after consultation with the profession. However, the promulgation of the relevant regulations was delayed for anotheryear, resulting in a delay in the development of the new qualifications and the scope of practice in line with the Nursing Act 33 of 2005, which is critical to the SANC's ability to fulfil its mandate as a regulato ry body.

The delays have serious implication for both nursing education and nursing practice. For instance, the nursing education institutions are unable to develop or revise curricula in response to the Nursing Act 33 of 2005 and the related scope of practice. Regulations in this regard, including the scope of practice, are important in the establishment and revision of curricula as they provide guidelines and set minimum requirements for each profession. Consequently, because the profession is still awaiting the new regulations, nothing is done to update current curricula.

Without a new scope of practice, it is difficult to handle the grey areas between the scope of practice of nurses and other health professionals. In developing the scope of practice in line with the Nursing Act 33 of 2005, a consultation process was introduced to ensure the participation of nurses and midwives. This consequently increased the time span of the process, resulting in criticism from those who were not aware of the consultative processes involved and who therefore believed that nothing was being implemented. The SANC needs to improve communication with its stakeholders so as to inform them of new developments and achievements. Without such communication, criticism will continue.

\section{The implementation of continuous professional development (CPD) for nursing}

Continuous professional development is said to be an invaluable system for ensuring that practitioners remain competent in their chosen professions. Most health professionals have successfully implemented this system for the maintenance of the licensure of practitioners in South Africa. The SANC also recognised the importance of continuous professional development to midwives and nurse practitioners, enabling them to retain their registration, as indicated in section 39 of the Nursing Act 33 of 2005. However, there has been a noticeable delay in the implementation of continuous professional 
development, a system which has now been under discussion for al most a decade. This has resulted in criticism of the SANC by its own members, who compare themselves with other heal th professionals within the multidisciplinary team which has successfully implemented the CPD. This delay is seen as a contributing factor to the ongoing deterioration of the professional status of nurses and midwives and failure of the SANC as a regulatory body to provide the public with competent nursing practitioners whose professional development is continuously being monitored.

In preparation for the successful implementation of CPD, the SANC has held numerous consul tative forums with national nurse researchers who have conducted studies on CPD and international benchmarking exercises in order to find the best model for implementing CPD for nursing and midwifery practitioners. As a regulatory body with different categories of nurses and midwives, the SANC has to ensure that the model chosen for the implementation of CPD is ideal, practical and feasible for all such personnel. The SANC needs to consider the complexity of the professional requirements demanded from the different nursing and midwifery categories

in terms of them retaining their individual registration according to each specialized category rather than in relation to an umbrella CPD system.

\section{The umbrella regulation of Nursing and Midwifery}

Another criticism of the SANC is its failure to recognise nursing and midwifery as two distinct professions as is the case with other countries where these two professions are regulated by national Nursing and Midwifery Boards. In South Africa, the nursing and midwifery professions are regulated by the same body, the South African Nursing Council through the Nursing Act 33 of 2005. Complaints come from some midwives who feel that they are not receiving the same recognition as their international counterparts. This is not far-fetched as such recognition was already proposed and adopted by the International Midwifery Council in 2005 in the framework for legislation to govern midwifery practice. This framework provides a mechanism for a regulatory body that is governed by midwives with the aim of protecting the public and improving maternal, child and public health. The structure recognises the importance of separate midwifery regulations and legislation which supports and enhances the work of midwives (ICM, 2011).

Although separating the two professions is seen to be an easy option, certain considerations have to be made, specifically with reference to the education and training of professional nurses. The comprehensive nursing education and training programme that was introduced in the country by the South African Nursing Council in 1985 (R425) resulted in comprehensively trained professional nurses and midwives. This was a response to the national health needs of the country, in terms of which a comprehensively trained nurse and midwife is able to render nursing care to all those in need, including pregnant women, in the absence of medical practitioners. Regulating the two professions separately means an annulment of R425. Cognisance should be taken that the health services of the country might find it difficult to staff rural and community services with professional nurses who are qualified in one area alone. Separating the two professsions would require that a new curriculum for entry-level midwives be developed, including an appropriate career ladder for midwife practitioners. The International Confederation of Midwives will prove to be a useful resource on this. 
An easy solution to the separate regulation of the nursing and midwifery professions would be the inclusion of the word "Midwifery" into the South African Nursing Council so as to establish a new South African Nursing and Midwifery Council, as is the case with some African countries, including Botswana, Malawi, Nigeria and Tanzania. The question remains as to whether this would be acceptable to midwives or whether they would prefer a separate South African Midwifery Council. The latter seems to be an expensive option which would require additional material and human resources. Moreover, this would demand extensive consultation with the countries who have opted for the separation of the two professions. The United States of America regulates the Certified Professional Midwives separately from nurses and therefore would be the best country for to be used by the SANC as a benchmark (NACPM, 2008).

South African midwives need to rise to the challenge and work towards the recognition of their profession so that midwifery becomes a self-regulatory profession separate from nurses. Criticising the SANC for a failure to recognise midwives will then cease.

\section{Development and recognition of additional qualifications}

A serious criticism of the SANC over the years has involved its tardiness to respond to the ever-changing health care needs of the population, as well as to new developments in health care technology and medical and health science. This has come from different nursing forums and the nursing summit of 2011 where the example of the list of specialist nursing qualifications approved by the SANC was cited as limited and outdated. The addition of new and internationally recognised nursing qualifications such as forensicnursing was highlighted as one such example.

In responding to the population's health needs and new developments nationally and internationally, some higher education institutions have developed relevant nursing education programmes despite the fact that these are not approved as additional qualifications by the SANC. Without the SANC'S involvement in the approval or accreditation of such qualifications, the public is exposed to unregulated, but nevertheless essential nursing specialist programmes.

Section 31(2) of the Nursing Act of 2005 mandates the Minister of Health, in consultation with the South African Nursing Council, to create other levels and types of nursing specialisations. This should include other nursing qualifications considered essential to the publicinterest. The South African Nursing Council therefore has a responsibility by virtue of the Nursing Act of 2005 to respond to the evolving health needs and new technological developments in health by being prepared to regulate additional nursing qualifications not currently enumerated on their list of approved qualifications. It is in the interest of the public and the nursing profession that the SANC develops a process for the recognition of new specialties in nursing based on consultation with the profession, and that some of the urgently needed specialties be recognized as soon as possible.

\section{Conclusion}

One of the main achievements of the South African Nursing Council since 1994 was the unification of the nursing profession within one regulatory body within the Republic. This was achieved by abolishing all the homeland nursing councils through an uneventful, but successful transition to one national 
Trends in Nursing, Vol. 1, Issue 1, 2012 http://fudisa .joumals.ac.za http://dx.doi.org/10.14804/1-1-20 regulatory body. This provides uniform national protection for the citizens of this country, irrespective of which province or area they reside.

The South African Nursing Council obtained the SAQA accreditation status as an ETQA and thus retained its function of regulating nursing education and training in collaboration with the HEQC. The management of the ETQA status is crucial for the SANC to continue regulating the education and training of nurses and midwives in the country.

The regulation of the nursing profession is a dynamic process. The SANC needs constantly to respond to national and international changes in legislation and policies. Nurses and midwives in both public and private health and education institutions have a role to play in assisting the SANC to regulate the nursing profession and protect the public.

\section{References}

International Confederation of Midwives, 2011. Global standards for midwifery regulation. 7 December 2012. www.internationalmidwives.org.

Issue Brief. 2008. Certified professional midwives in the United States. www.nacpm.org.

Marock, C. 2000. Quality assurance in higher education: the role and approach of professional bodies and SETSs to quality assurance. Integrated Summary, a report commissioned by the Higher Education Quality Committee.

NACPM (2008) Issue Brief. 2008. Certified professional midwives in the United States. www.nacpm.org.

South Africa, 1997. Higher Education Act (No.101 of 1997). Pretoria: Gove rnment Printers.

South Africa, 1995. South African Qualifications Authority Act (No. 58 of 1995). Pretoria: Government Printers.

South Africa, 1995. Nursing Ammendment Act (No.547of 1995). Pretoria: Government Printers.

South Africa, 2005. Nursing Act (No.33 of 2005). Pretoria: Government Printers.

Subedar, H.2001. South African Nursing Council as an Education and Training Quality Authority. Circular 13/2001. 5 December 2011. www.sanc.co.za/archive/2001/newsc.113.htm 